\title{
Evaluating the Long Performance of Asphalt Overlays using Reclaimed Asphalt Pavements (RAP)
}

\author{
Ahmed Ebrahim Abu El-Maaty*, Alaa B. Fathy and Saad A. El-Hamrawy \\ Civil Eng. Dept., Faculty of Engineering, Menoufia University, Egypt. \\ *(Corresponding author: maaty5000@yahoo.com)
}

\begin{abstract}
In Long Term Pavement Performance (LTPP) assessment process, the specific pavement studies were designed to investigate the factors affecting pavement rehabilitation such as overlay thickness (51 and $127 \mathrm{~mm}$ ), asphalt overlay materials (raw compared with adding $30 \%$ reclaimed asphalt pavement (RAP)) and surface curing type before rehabilitation (low and heavy). In this study, data from 4 sites were taken to perform analysis where each site consists of 8 sections (4 sections with raw materials and another 4 sections using 30\%RAP). Each section was $152.4 \mathrm{~m}$ long and $3.66 \mathrm{~m}$ wide. These sites were selected due to their similar climate to Egypt. Four performance indicators were chosen including fatigue cracking, longitudinal cracking, rutting, and roughness. A statistical analysis using the paired t-tests, p-values and analysis of variance (ANOVA) were achieved to determine the priority in performance and the significance in variation. The results that based on practical observations have indicated that the RAP sections achieved similar/ better performance as compared with raw sections especially at higher thickness except for rutting. The climate had no obvious effect on fatigue cracking development while dry climate provided higher longitudinal cracking and roughness progress for RAP sections. Statically, the variation in pre-overlay curing (from low to heavy) had the highest statistical effect on fatigue cracking increasing, while rutting and roughness progresses weren't clearly affected by variation in climate, thickness or curing.
\end{abstract}

Keywords: rehabilitation, asphalt overlay, long term performance, RAP, cracking.

\section{Introduction}

Deterioration of the pavement may contribute to pavement distresses which then causes several problems especially in developing countries such as Egypt. The most common distress types occurring in the Egyptian roads are rutting, cracking, roughness, etc. Thus, continuous rehabilitation is needed for successive years to overcome the distresses related to materials, traffic and environmental conditions. The most effective mean for pavement rehabilitation is using overlays [1, 2]. Continues destruction of flexible pavements provides huge amounts of solid remnants. With decreasing of landfill areas, raw aggregates and asphalt, the recycling of asphalt pavement wastes has turned into an important issue around the world in the last years [3, 4]. Despite of that, the long term performance of hot asphalt mixtures containing reclaimed asphalt pavement (RAP) has not been satisfactorily investigated yet. These investigations are extremely helpful in evaluating the life cycle assessment of pavements including RAP [5, 6].

The Long-Term Pavement Performance (LTPP) program in the United States (U.S.) and Canada gathered and analyzed information over a long period (approximately 20 years) and investigated the factors affecting pavement performance such as materials, climatic, traffic loads, building parameters and rehabilitation treatments [7, 8]. The Specific Pavement Studies Experiment 5 (SPS-5) was prepared to investigate the impacts of overlay rehabilitation where the growth of cracks, plastic deflection or rutting, and roughness had been accurately observed $[9,10]$. Thence, an amount of long term performance information was produced where 4 sites for the SPS-5 were selected and studied according to their climate, which similar to the Egyptian climate. Each site included 8 test sections (4 using raw materials and 4 using 30\%RAP) constructed and operated under the same conditions.

Few previous researches that studied rehabilitation methods have been carried out using the LTPP database. Their results concluded that the long term performance indicators such as cracking, plastic deflection or rutting and roughness have not changed significantly at using raw or RAP-including mixes, also at using low or heavy pre-overlay curing [11, 12]. Although the previous studies provided helpful 


\section{Ahmed E. Abu El-Maaty, Alaa B. Fathy and Saad A. El-Hamrawy "Evaluating the long performance of asphalt overlays using reclaimed asphalt pavements $(R A P)^{\prime \prime}$}

outputs, the potential reacting impacts between overlay thickness and surface curing before rehabilitation have not been studied thoroughly. Moreover, the performance of asphalt overlays including RAP has not been highlighted clearly [13] . The main objective of this study is evaluating the long-term performance of asphalt overlays utilizing $30 \%$ RAP material as compared with using only raw materials. Moreover, the overlay thicknesses of 51 and $127 \mathrm{~mm}$ representing as a thin and a thick thickness respectively are investigated. Rehabilitation with and without grinding of the standing surface is also considered. The four performance indicators (deteriorations groups) which were chosen for this study are containing fatigue cracking, longitudinal cracking, rutting, and roughness.

\section{Methodology}

\subsection{Selecting data from LTPP}

According to Köppen climate classification, which is one of the most widely used climate classification systems. It was first published by the GermanRussian climatologist Wladimir Köppen [14], Egypt basically has a hot desert climate. The climate is in general extremely dry all over the country except on the northern Mediterranean coast which receives rainfall in winter. In addition to scarcity of rain, extreme heat during summer months is also a general climate feature of Egypt although daytime temperatures are more moderated along the northern coast. Based on that, the climate of Egypt is classified as not freeze and dry all over the country, and not freeze/wet at the northern Mediterranean coast.

For this research, the practical observations of pavement performance for (SPS-5) were taken from LTPP database. Data in the observation unit contains deterioration registrations for fatigue cracking, longitudinal cracking, average rutting depths and global roughness index. Four test sites from LTPP database (SPS-5) were selected for this study where their climates are similar to Egypt. Table (1) illustrates the selected sites from different states. Each site contained 8 sections to clarify the effect of overlay thickness (thin or thick), pre-overlay curing (low or heavy grinding of the standing pavement before rehabilitation) and overlay materials types (raw material only or combined with $30 \%$ RAP) on their long term performance. Table (2) shows descriptions for the pavement sections studied in this research.
Table 1- The selected sites from LTPP database

\begin{tabular}{|c|c|c|c|}
\hline \multicolumn{2}{|c|}{ Not freeze/wet climate } & \multicolumn{2}{c|}{ Not freeze/dry climate } \\
\hline 198 ee & $\begin{array}{c}\text { Construction } \\
\text { Year }\end{array}$ & Site Name & $\begin{array}{c}\text { Construction } \\
\text { Year }\end{array}$ \\
\hline Alabama & 1991 & Arizona & 1990 \\
\hline Maryland & 1992 & $\begin{array}{c}\text { New } \\
\text { Mexico }\end{array}$ & 1996 \\
\hline
\end{tabular}

Table 2- Descriptions for the selected pavement sections

\begin{tabular}{|c|c|c|c|c|}
\hline $\begin{array}{c}\text { Thickness of } \\
\text { Overlay }\end{array}$ & \multicolumn{4}{|c|}{ Thin thickness (51mm) } \\
\hline $\begin{array}{c}\text { surface curing before } \\
\text { rehabilitation }\end{array}$ & \multicolumn{2}{|c|}{ No/low grinding } & \multicolumn{2}{c|}{ Heavy grinding } \\
\hline Section number (ID) & 505 & 502 & 506 & 509 \\
\hline Materials types & Raw & RAP & Raw & RAP \\
\hline $\begin{array}{c}\text { Thickness of } \\
\text { Overlay }\end{array}$ & \multicolumn{4}{|c|}{ Thick thickness (127mm) } \\
\hline Section number (ID) & 504 & 503 & 507 & 508 \\
\hline Materials types & Raw & RAP & Raw & RAP \\
\hline
\end{tabular}

\subsection{Analysing of data}

After selecting data, the long term performance of asphalt overlay is analyzed using comparisons between the different studied parameters such as overlay thickness, surface curing before rehabilitation and material types. The effects of these parameters are evaluated on each deterioration group considered in this study. The first analysis used in this study is by plotting the extracted data for each investigated parameter on one graph to illustrate the potential variation.

The second analytical method used in this study is the paired-sample t-test to measure the difference between the progress of each studied distress (such as crakes, rutting and roughness) for RAP and raw sections at the same conditions utilizing SPSS program by deducting the deterioration values of the raw section from the values for RAP section [3]. The t-test sign provides thoughts on variance between the long term performance of raw and RAP when used in asphalt overlay. Thus, if the t-value has a negative sign for a certain distress, hence the performance of RAP section is better than raw section [15]. T-test can be calculated through the following equations [15]:

$$
T=\text { Mean diff. } / S E
$$




$$
\mathrm{SE}=\frac{S d}{\sqrt{n}}
$$

Where: Mean diff. is the mean of difference between RAP and virgin sections, SE is the standard error of the mean difference, $\mathrm{Sd}$ is the stander deviation and $\mathrm{n}$ is the number of sections using RAP and virgin mixtures together.

Using $\mathrm{t}$ value and degree of freedom $(\mathrm{df}=\mathrm{n}-1)$, the $\mathrm{P}$-value can be determine as a significance index $(\alpha)$ for the difference between RAP and raw sections performances. Traditionally, the cut-off value to reject the null hypothesis $(\alpha)$ is 0.05 , which means that when no significant difference exists. Thus, the difference between RAP and raw sections becomes significant when $(\alpha<0.05)$ [9]. The third analytical method used is analysis of variance (ANOVA) which provides a statistical procedure interested with comparing means of many samples [16].

\section{Results and Discussion}

\subsection{Fatigue cracking}

The first deterioration group studied in this research is fatigue cracking which is measured in crack area by $\left(\mathrm{m}^{2}\right)$. To study the fatigue cracking development in asphaltic overlay at the long term in wet/not freeze climate, two sites were considered (Alabama and Maryland). For dry/not freeze climate, two sites were considered (Arizona and New Mexico). Figures (1 and 2) show the fatigue cracking development for two sites representing wet climate. Each Figure illustrates 4 diagrams containing 8 pavement sections code (ID) from LTPP as defined in Table (2). These four diagrams are representing two overlay thicknesses (51 and $127 \mathrm{~mm}$ ) and two pre-overlay curing methods (No/low grinding and heavy grinding). Each diagram clarifies two materials types used in construction of asphalt overlay mixtures (completely raw and mixed with $30 \%$ RAP).

Generally, it can be concluded that with increasing service life of the constructed asphalt overlay, the fatigue cracking development increases pointedly and severely in Alabama especially at terminal observed periods. Moreover, the RAP and raw sections at first provide fatigue cracking development at the same rate, but in a long term RAP sections show higher fatigue cracking. Moreover, the difference in fatigue development between RAP and raw sections is rather small at thick overlay thickness $(127 \mathrm{~mm})$ while this difference becomes larger at thin overlay thickness $(51 \mathrm{~mm})$. Thus it can be said that using $30 \%$ RAP gives better long term performance of asphalt overlay according to fatigue cracks development. For second SPS-5 site in wet climate (Maryland), it can be observed that the fatigue performance of RAP and raw sections are almost identical at many points. It is striking that RAP sections show lower fatigue cracking at many points confirming its long-term effectiveness as compared with virgin materials. The pre-overlay curing cases (No/low grinding and heavy grinding) don't have any obvious effect on fatigue development in a long run.

Figure (3) illustrates the fatigue cracking for two sites representing dry climate. It can be observed that the RAP sections show fatigue cracking development higher than raw sections at the last years of observation in most sections in Arizona site. The RAP section 509 appears a sudden increased deterioration at the last years of observation as compared with raw section 506. Better result for RAP sections is achieved in New Mexico site (Figure 4) where they provide fatigue performance identical or even better than virgin materials in long term. Generally thicker overlay provides better results for RAP sections. The surface grinding before rehabilitation doesn't appear any noticeable difference in fatigue cracking. Most RAP sections perform worse than/identical with raw sections according to fatigue cracking development in long term performance in wet and dry climate especially at terminal observed periods. Table (3) illustrates the ttests and the P-values for fatigue cracking development.

As shown in Table (3), for wet climate, mostly raw sections perform significantly better than RAP sections in Alabama. For thinner overlay thickness $(51 \mathrm{~mm})$ in Maryland site, RAP sections perform significantly better than raw sections. While for thicker overlay thickness $(127 \mathrm{~mm})$ in Maryland, raw sections perform insignificantly better than RAP sections. For dry climate, using RAP improves the performance insignificantly in New Mexico, while raw sections provide better performance insignificantly in Arizona. Generally, it can be observed that RAP sections statistically achieve better insignificant performance in dry climate while they obtain worse significant performance in wet climate. 
Ahmed E. Abu El-Maaty, Alaa B. Fathy and Saad A. El-Hamrawy "Evaluating the long performance of asphalt overlays using reclaimed asphalt pavements $(R A P)^{\prime \prime}$
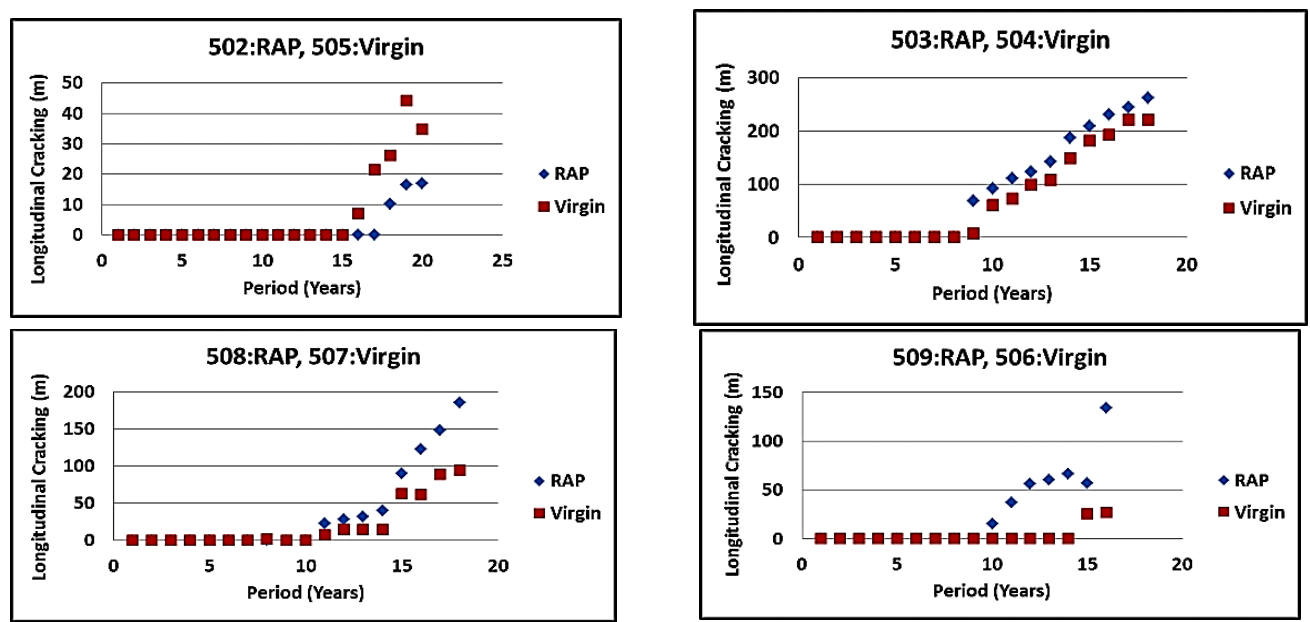

Figure 1- Fatigue cracking progress in Alabama (wet climate)
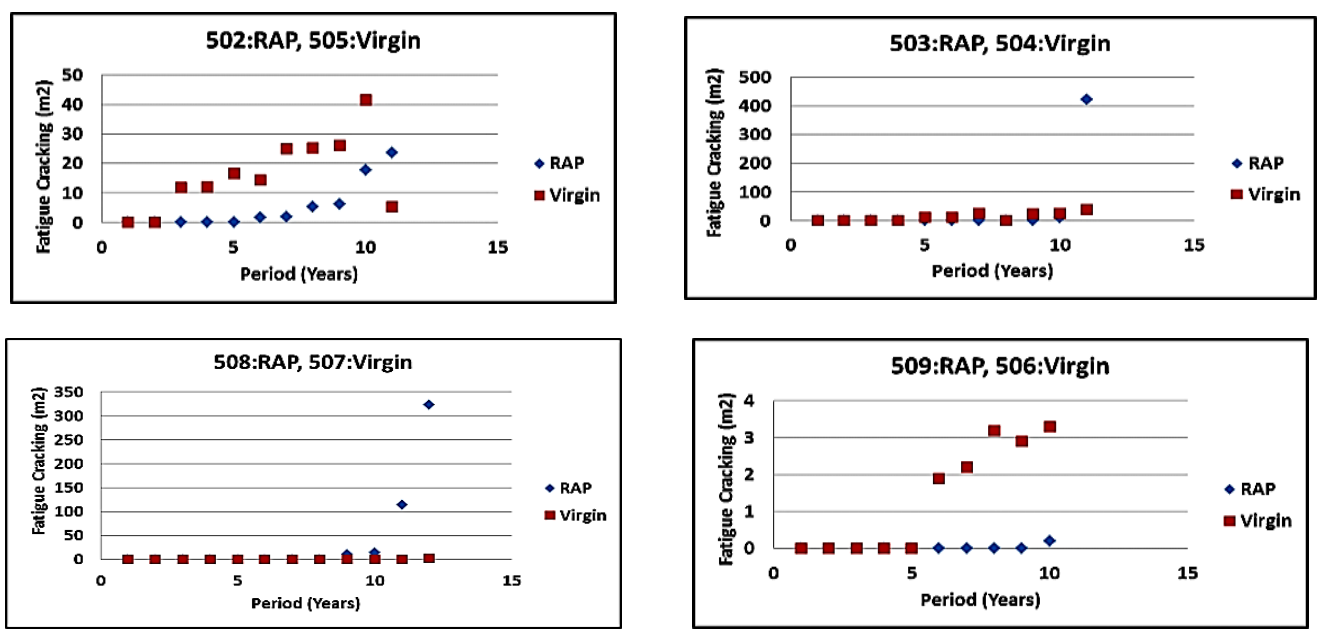

Figure 2- Fatigue cracking progress in Maryland (wet climate)
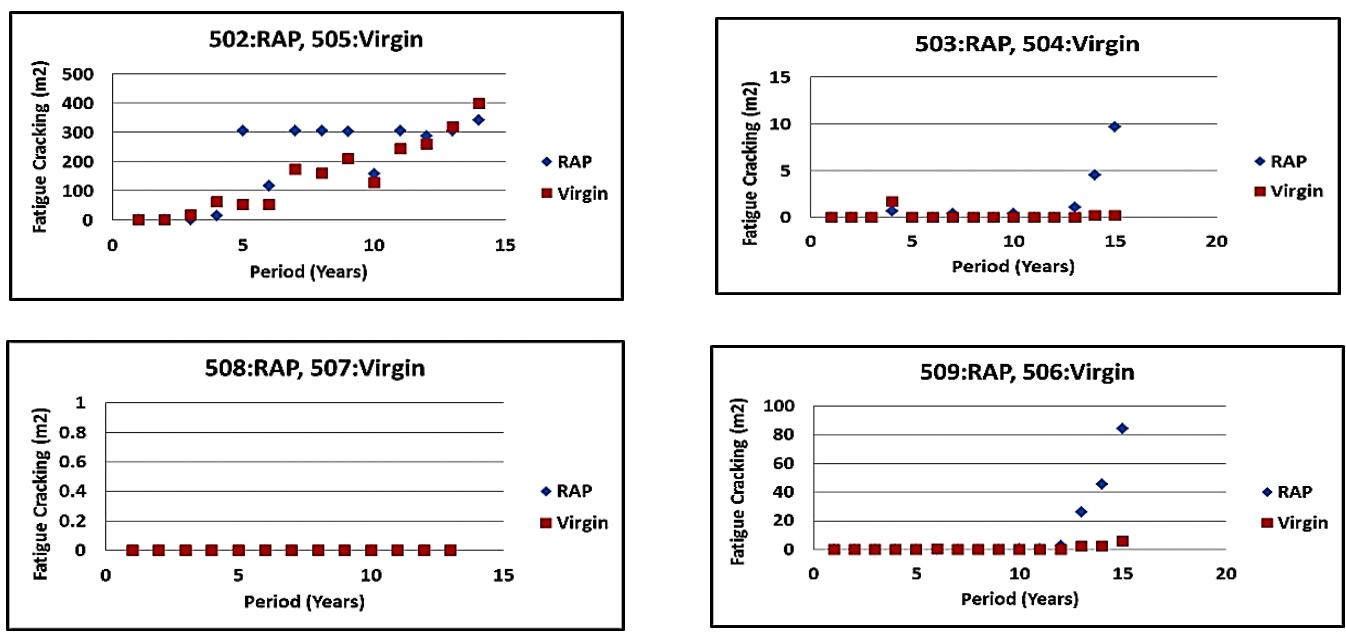

Figure 3- Fatigue cracking progress in Arizona (dry climate) 

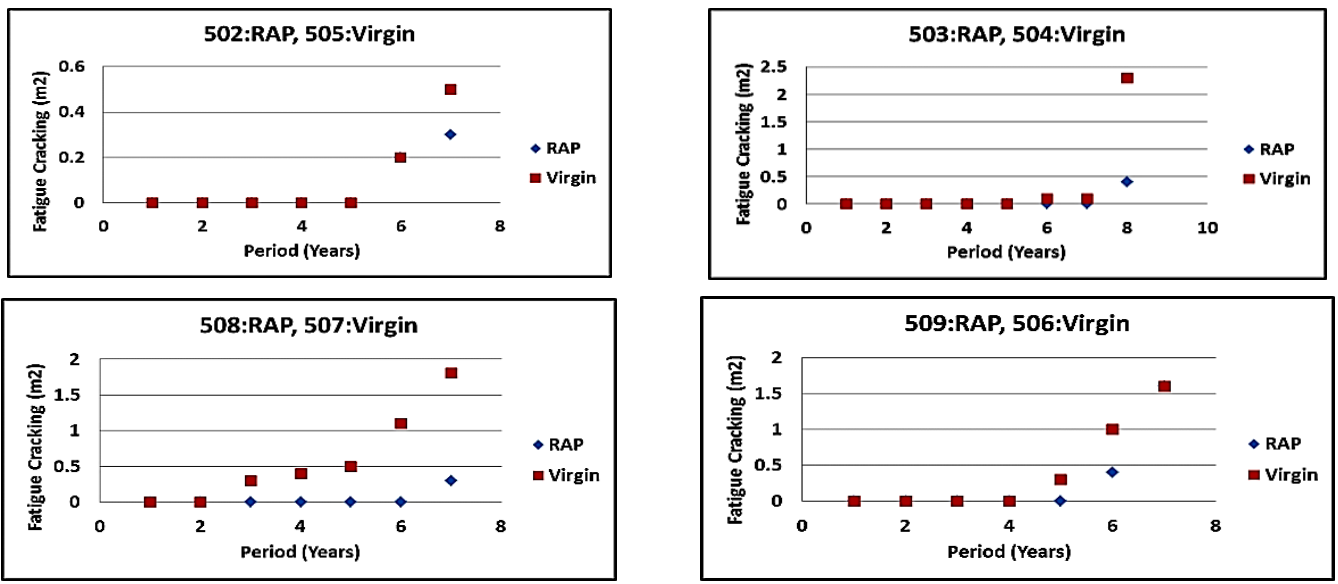

Figure 4- Fatigue cracking progress in New Mexico (dry climate)

Table 3- Paired t-tests and p-values for fatigue cracking development

\begin{tabular}{|c|c|c|c|c|c|c|c|c|c|c|}
\hline Climate & Site & Sections & $\begin{array}{c}\text { Mean } \\
\text { diff. } \\
\left(\mathbf{m}^{2}\right)\end{array}$ & Sd & SE & $\begin{array}{c}\text { t- } \\
\text { value }\end{array}$ & df & $\begin{array}{l}\text { p-value } \\
(\alpha=0.05)\end{array}$ & $\begin{array}{c}\text { Signi- } \\
\text { ficance }\end{array}$ & $\begin{array}{l}\text { Better } \\
\text { Perf. }\end{array}$ \\
\hline \multirow{8}{*}{ 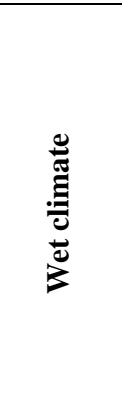 } & \multirow{4}{*}{ 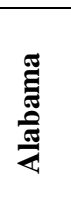 } & $502-505$ & 44.68 & 65.898 & 15.98 & 2.796 & 16 & 0.013 & Sign. & Raw \\
\hline & & 503-504 & 2.12 & 2.12 & 0.499 & 4.241 & 17 & 0.001 & Sign. & Raw \\
\hline & & $508-507$ & 8.36 & 7.24 & 1.76 & 4.757 & 16 & 0.000 & Sign. & Raw \\
\hline & & $\begin{array}{l}509-506 \\
\end{array}$ & 9.39 & 9.69 & 2.501 & 3.753 & 14 & 0.0002 & Sign. & Raw \\
\hline & \multirow{4}{*}{$\frac{\bar{E}}{\stackrel{E}{E}}$} & $502-505$ & -11.07 & 12.74 & 3.84 & -2.88 & 10 & 0.016 & Sign. & RAP \\
\hline & & 503-504 & 26.89 & 118.95 & 35.87 & 0.75 & 10 & 0.471 & Insign. & Raw \\
\hline & & 508-507 & 38.28 & 94.61 & 27.31 & 1.402 & 11 & 0.189 & Insign. & Raw \\
\hline & & 509-506 & -1.33 & 1.45 & 0.46 & -2.89 & 9 & 0.018 & Sign. & RAP \\
\hline \multirow{8}{*}{ 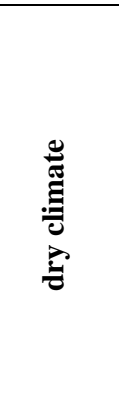 } & \multirow{4}{*}{ 营 } & $502-505$ & 47.88 & 85.06 & 22.73 & 2.106 & 13 & 0.055 & Insign. & Raw \\
\hline & & 503-504 & 0.98 & 2.63 & 0.679 & 1.443 & 14 & 0.171 & Insign. & Raw \\
\hline & & 508-507 & $\begin{array}{l}-0.90 \\
\end{array}$ & 3.49 & 0.90 & -1.00 & 14 & 0.334 & Insign. & RAP \\
\hline & & 509-506 & 9.97 & 22.58 & 5.829 & 1.710 & 14 & 0.109 & Insign. & Raw \\
\hline & \multirow{4}{*}{ 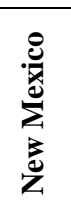 } & $502-505$ & -0.029 & 0.0756 & 0.029 & -1.00 & 6 & 0.356 & Insign. & RAP \\
\hline & & $503-504$ & -0.26 & 0.663 & 0.234 & -1.12 & 7 & 0.30 & Insign. & RAP \\
\hline & & $508-507$ & $\begin{array}{l}-0.54 \\
\end{array}$ & 0.562 & 0.213 & -2.55 & 6 & 0.043 & Sign. & RAP \\
\hline & & 509-506 & -0.13 & 0.236 & 0.089 & -1.44 & 6 & 0.20 & Insign. & RAP \\
\hline
\end{tabular}

\subsection{Longitudinal cracking}

Figures (5 and 6) illustrate the longitudinal cracking performance of the four SPS-5 pavement sections in Alabama and Maryland respectively representing wet climate. It's clarified that RAP sections give similar or better performance for longitudinal cracking than raw sections in long run especially in two sections (502 in Alabama and 509 in Maryland).

The thicker overlay thickness $(127 \mathrm{~mm})$ provides better results where it shows more rapprochements between RAP and raw sections in favor of RAP sections. Figures (7 and 8) clarify the longitudinal cracking progress in Arizona and New Mexico respectively representing dry climate. It can be observed that in dry climate, RAP sections perform worse than raw sections such as sections 503 and 508 in Arizona and 509 in New Mexico. Thus it can be concluded that unlike fatigue cracking, thinner overlay thickness may provide better long term performance for RAP sections against longitudinal cracking development as shown in section 502 in 


\section{Ahmed E. Abu El-Maaty, Alaa B. Fathy and Saad A. El-Hamrawy "Evaluating the long performance of asphalt overlays using reclaimed asphalt pavements $(R A P)^{\prime \prime}$}

Arizona. The surface curing before rehabilitation hasn't any obvious effect in longitudinal cracking. Generally, most RAP sections provide better or convergent performance in wet climate and worse performance in dry climate according to longitudinal cracking development.
From the statistical analysis shown in Table (4), it can be observed that mostly RAP sections perform significantly worse than raw sections for both wet and dry climates.
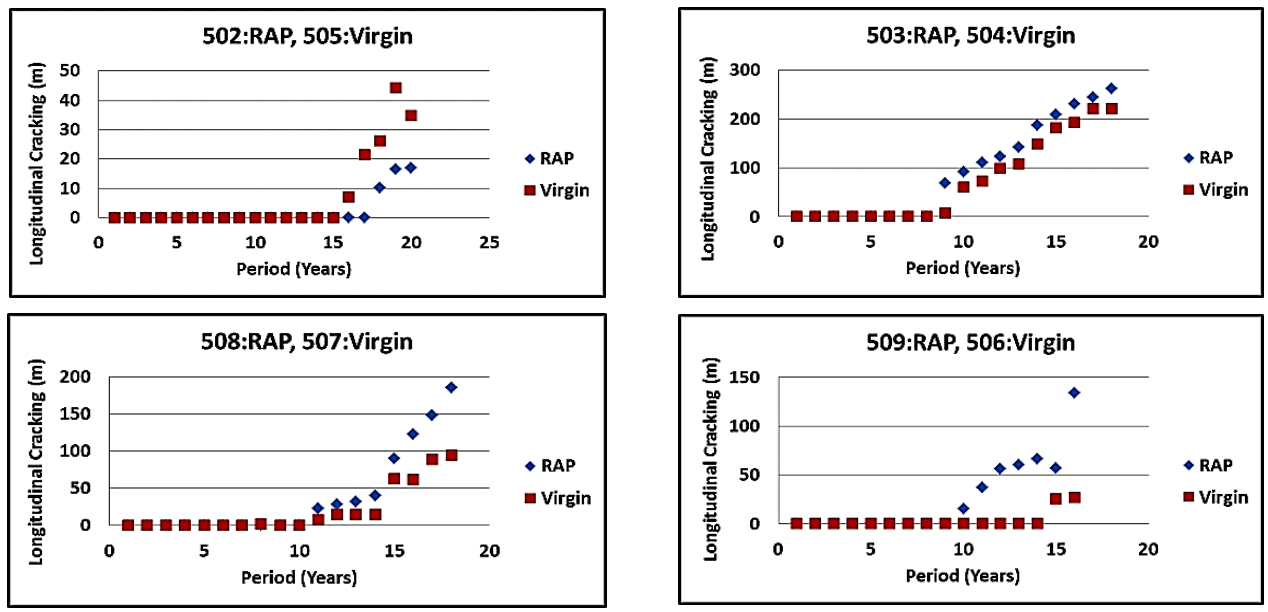

Figure 5- Longitudinal cracking development in Alabama (wet climate)
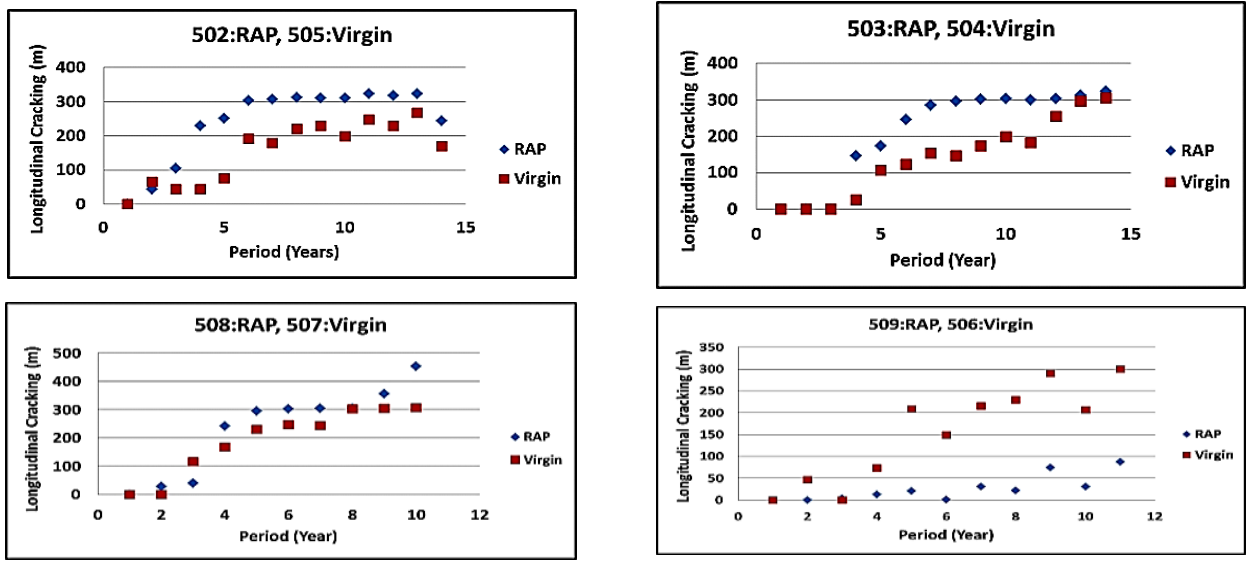

Figure 6- Longitudinal cracking development in Maryland (wet climate)
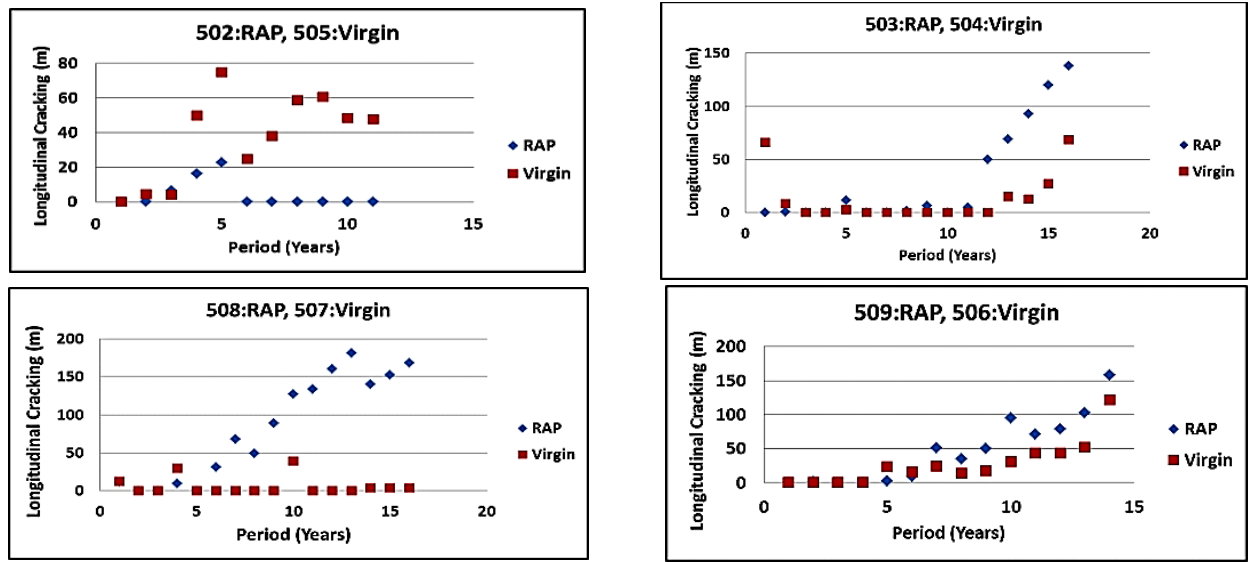

Figure 7: Longitudinal cracking development in Arizona (dry climate) 

of asphalt overlays using reclaimed asphalt pavements $(R A P) "$
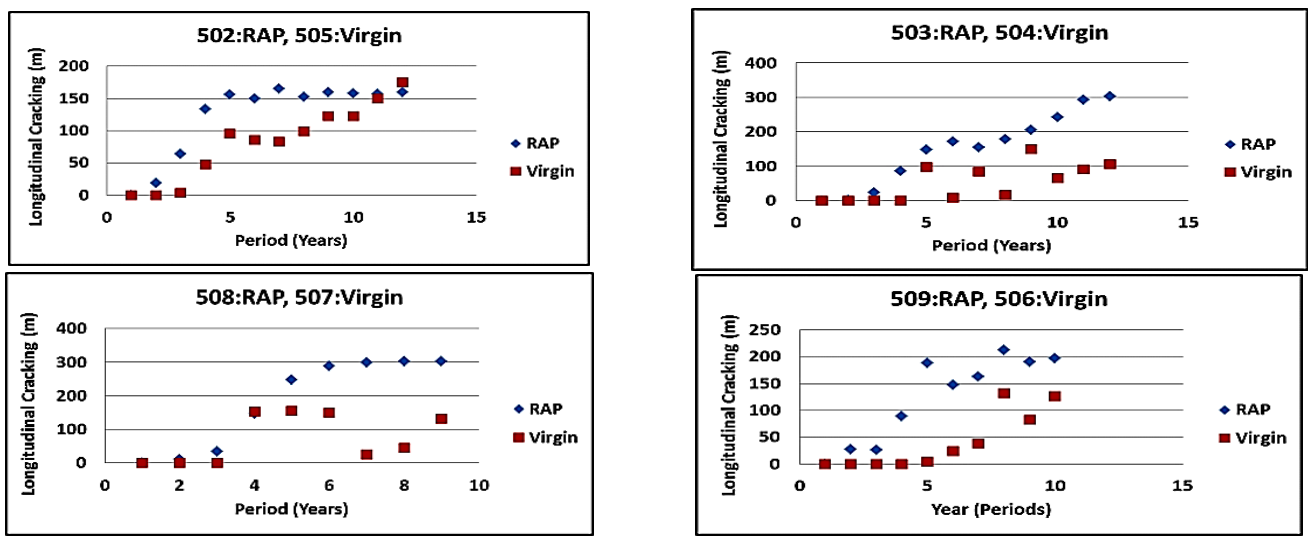

Figure 8- Longitudinal cracking development in New Mexico (dry climate)

Table 4- Paired t-tests and p-values for longitudinal cracking development

\begin{tabular}{|c|c|c|c|c|c|c|c|c|c|c|}
\hline Climate & Site & Sections & $\begin{array}{l}\text { Mean } \\
\text { diff. } \\
\text { (m) }\end{array}$ & Sd & SE & $\begin{array}{c}\mathrm{t}- \\
\text { value }\end{array}$ & df & $\begin{array}{l}\text { p-value } \\
(\alpha=0.05)\end{array}$ & $\begin{array}{l}\text { Signifi- } \\
\text { cance }\end{array}$ & $\begin{array}{l}\text { Better } \\
\text { Perf. }\end{array}$ \\
\hline \multirow{8}{*}{ 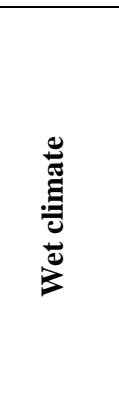 } & \multirow{4}{*}{ 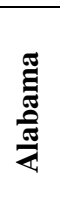 } & $502-505$ & -4.485 & 8.709 & 1.947 & -2.30 & 19 & 0.033 & Sign. & RAP \\
\hline & & 503-504 & 19.90 & 20.051 & 4.726 & 4.21 & 17 & 0.001 & Sign. & Raw \\
\hline & & $\begin{array}{l}508-507 \\
\end{array}$ & 17.05 & 26.981 & 6.360 & 2.68 & 17 & 0.016 & Sign. & Raw \\
\hline & & 509-506 & 23.256 & 33.103 & 8.276 & 2.81 & 15 & 0.013 & Sign. & Raw \\
\hline & \multirow{4}{*}{ 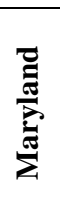 } & $502-505$ & 86.807 & 56.76 & 15.17 & 5.722 & 13 & 0.000 & Sign. & Raw \\
\hline & & 503-504 & 72.907 & 57.32 & 15.32 & 4.759 & 13 & 0.000 & Sign. & Raw \\
\hline & & $508-507$ & 40.58 & 58.57 & 18.52 & 2.191 & 9 & 0.056 & Insign. & Raw \\
\hline & & 509-506 & -130.6 & 86.85 & 26.185 & -4.99 & 10 & 0.001 & Sign. & RAP \\
\hline \multirow{8}{*}{ 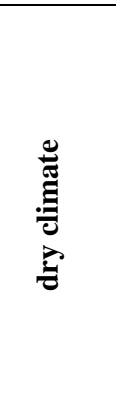 } & \multirow{4}{*}{ 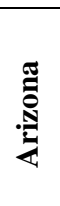 } & $502-505$ & -33.27 & 23.463 & 7.074 & -4.70 & 10 & 0.001 & Sign. & RAP \\
\hline & & $503-504$ & 18.425 & 40.387 & 10.097 & 1.825 & 15 & 0.088 & Insign. & Raw \\
\hline & & $508-507$ & 76.938 & 70.31 & 17.577 & 4.377 & 15 & 0.001 & Sign. & Raw \\
\hline & & 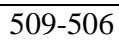 & 18.979 & 24.065 & 6.432 & 2.951 & 13 & 0.011 & Sign. & Raw \\
\hline & \multirow{4}{*}{ 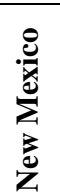 } & $502-505$ & 40.77 & 32.509 & 9.384 & 4.344 & 11 & 0.001 & Sign. & Raw \\
\hline & & 503-504 & 99.083 & 76.846 & 22.184 & 4.467 & 11 & 0.001 & Sign. & Raw \\
\hline & & $508-507$ & 107.88 & 108.732 & 36.244 & 2.976 & 8 & 0.018 & Sign. & Raw \\
\hline & & $509-506$ & 83.63 & 55.598 & 17.582 & 4.757 & 9 & 0.001 & Sign. & Raw \\
\hline
\end{tabular}

\subsection{Rutting}

Figures (9 and 10) clarify the overlay rutting performance in Alabama and Maryland respectively representing wet climate. It can be concluded that the pre-overlay curing has an obvious effect on the performance against rutting where the heavy surface grinding before rehabilitation provides worse performance for RAP sections except section 508 in Maryland. For no/low pre-overlay curing, RAP sections provide rutting values convergent with raw sections. For dry climate sections in Arizona and

New Mexico, Figures (11) shows that using RAP in overlay mixtures provides lower performance for all sections in Arizona except section 508. While Figure (12) illustrates that using RAP in overlay mixtures shows better/close performance as compared with raw sections for all sections in New Mexico. Generally, it can be observed that the heavy surface grinding before rehabilitation has a clear impact in reducing the long term performance of RAP sections 


\section{Ahmed E. Abu El-Maaty, Alaa B. Fathy and Saad A. El-Hamrawy "Evaluating the long performance of asphalt overlays using reclaimed asphalt pavements $(R A P)^{\prime \prime}$}

against rutting in wet climate. While in dry climate, the pre-overlay curing hasn't any clear impact on the performance where RAP sections provide slight worse performance in Arizona and convergent (slight better) performance in New Mexico. Moreover, the overlay thickness hasn't obvious effect on rutting development in both wet and dry climate. Table (5) illustrates the statistical analysis of the rutting development that emphasizes the previous observations. For wet climate, heavy surface grinding before rehabilitation shows that the performance of RAP sections against rutting is significantly worse than raw sections except section 508 in Maryland.
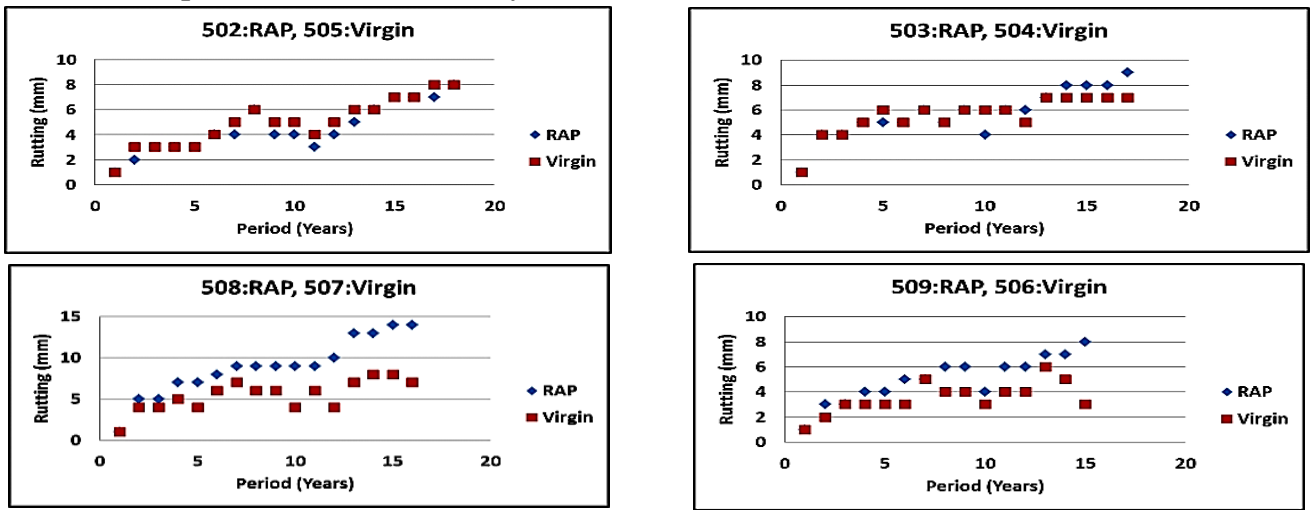

Figure 9- Rutting development in Alabama (wet climate)
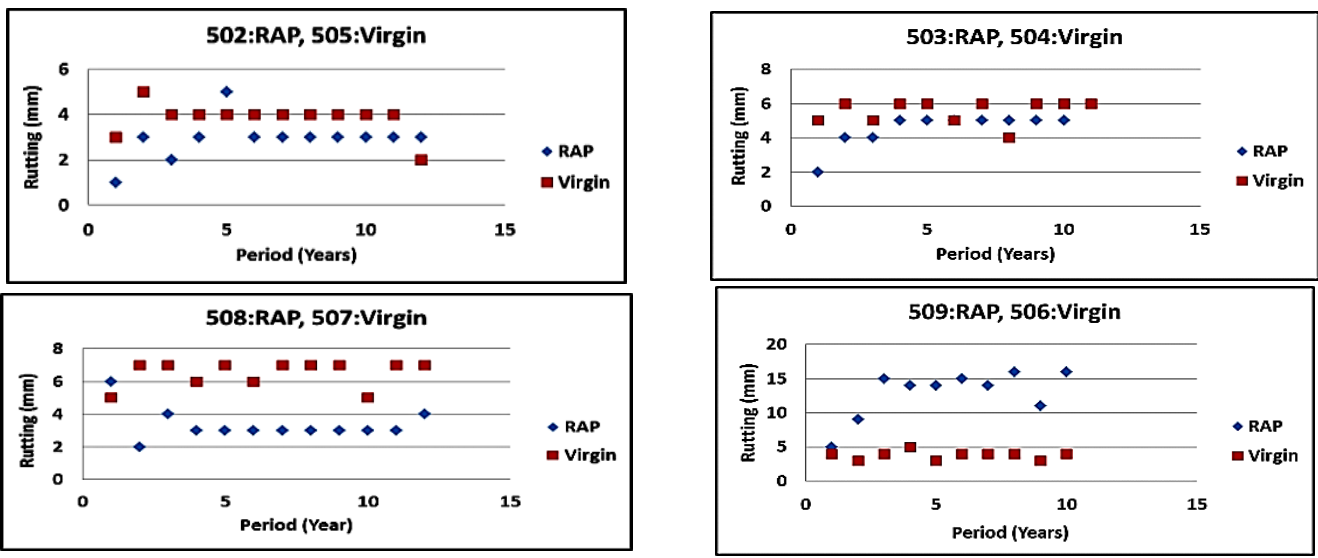

Figure 10- Rutting development in Maryland (wet climate)
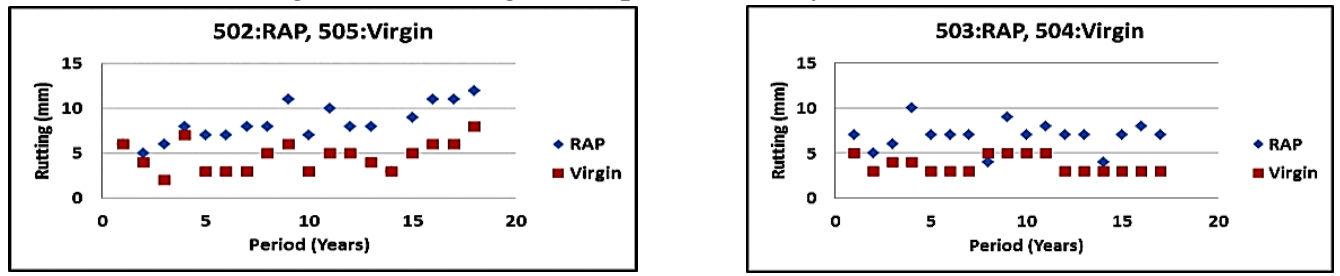
Ahmed E. Abu El-Maaty, Alaa B. Fathy and Saad A. El-Hamrawy "Evaluating the long performance of asphalt overlays using reclaimed asphalt pavements $(R A P) "$
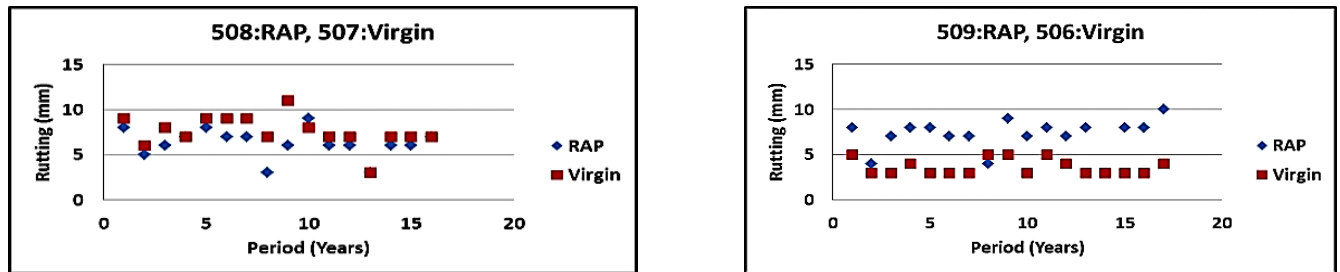

Figure 11- Rutting development in Arizona (dry climate)
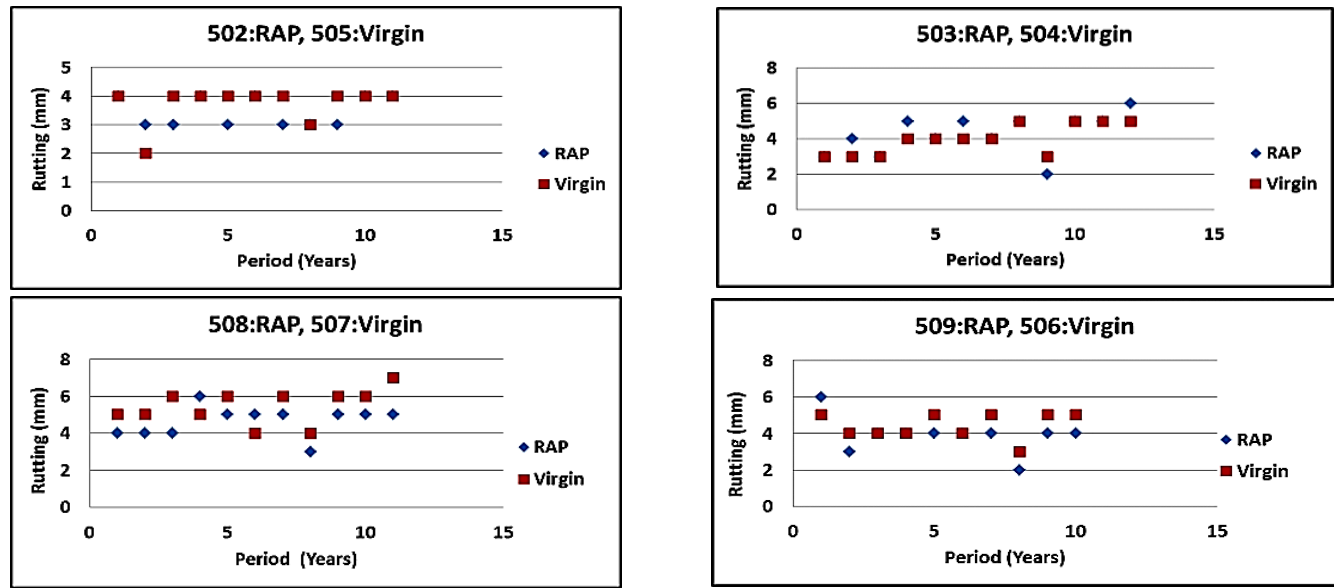

Figure 12- Rutting development in New Mexico (dry climate)

Table 5- Paired t-Tests and p-values for rutting development

\begin{tabular}{|c|c|c|c|c|c|c|c|c|c|c|}
\hline Climate & Site & Sections & $\begin{array}{c}\text { Mean } \\
\text { diff. } \\
(\mathrm{cm})\end{array}$ & Sd & SE & $\begin{array}{c}\text { t- } \\
\text { value }\end{array}$ & df & $\begin{array}{l}\text { p-value } \\
(\alpha=0.05)\end{array}$ & $\begin{array}{l}\text { Signifi- } \\
\text { cance }\end{array}$ & $\begin{array}{c}\text { Better } \\
\text { Perf. }\end{array}$ \\
\hline \multirow{8}{*}{ 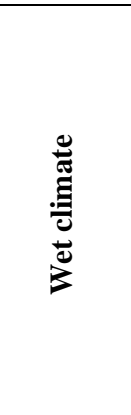 } & \multirow{4}{*}{ 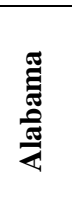 } & $502-505$ & -0.444 & 0.5113 & 0.1205 & -3.69 & 17 & 0.002 & Sign. & RAP \\
\hline & & $503-504$ & 0.1765 & 0.8828 & 0.2141 & 0.824 & 16 & 0.422 & Insign. & Raw \\
\hline & & $508-507$ & 3.4375 & 2.128 & 0.5320 & 6.461 & 15 & 0.000 & Sign. & Raw \\
\hline & & $509-506$ & 1.4667 & 1.246 & 0.3217 & 4.559 & 14 & 0.000 & Sign. & Raw \\
\hline & \multirow{4}{*}{ 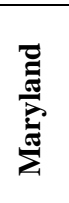 } & $502-505$ & -0.917 & 0.996 & 0.288 & -3.19 & 11 & 0.009 & Sign. & RAP \\
\hline & & $503-504$ & -0.91 & 1.04 & 0.315 & -2.89 & 10 & 0.016 & Sign. & RAP \\
\hline & & $508-507$ & -3.17 & 1.528 & 0.441 & -7.18 & 11 & 0.000 & Sign. & RAP \\
\hline & & $509-506$ & 9.100 & 3.414 & 1.08 & 8.43 & 9 & 0.000 & Sign. & Raw \\
\hline \multirow{8}{*}{ 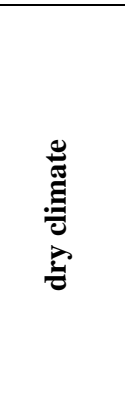 } & \multirow{4}{*}{ 通 } & $502-505$ & 3.389 & 1.7197 & 0.405 & 8.360 & 17 & 0.000 & Sign. & Raw \\
\hline & & $503-504$ & 3.176 & 1.667 & 0.404 & 7.856 & 16 & 0.000 & Sign. & Raw \\
\hline & & $508-507$ & -1.313 & 1.493 & 0.373 & -3.52 & 15 & 0.003 & Sign. & RAP \\
\hline & & $509-506$ & 3.471 & 1.875 & 0.455 & 7.633 & 16 & 0.000 & Sign. & Raw \\
\hline & \multirow{4}{*}{ 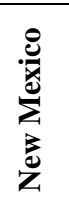 } & $502-505$ & -0.273 & 0.647 & 0.195 & -1.399 & 10 & 0.192 & Insign. & RAP \\
\hline & & $503-504$ & 0.250 & 0.622 & 0.179 & 1.393 & 11 & 0.191 & Insign. & Raw \\
\hline & & $508-507$ & -0.818 & 0.982 & 0.296 & -2.764 & 10 & 0.020 & Sign. & RAP \\
\hline & & $509-506$ & -0.500 & 0.707 & 0.224 & -2.236 & 9 & 0.052 & Insign. & RAP \\
\hline
\end{tabular}

\subsection{Roughness}

From the most important pavement performance indicator is the roughness which influences both passenger relief and car running effort and thus energy exhaustion. Moreover, roughness is usually utilized in life cycle assessment of pavements. The 


\section{Ahmed E. Abu El-Maaty, Alaa B. Fathy and Saad A. El-Hamrawy "Evaluating the long performance of asphalt overlays using reclaimed asphalt pavements $(R A P) "$}

international roughness index (IRI) is generally used to express roughness of pavement. IRI of $1.5 \mathrm{~m} / \mathrm{km}$ is considered as the roughness starting [17, 18]. The roughness development in Alabama and Maryland (as wet climate) is as shown in Figures (13 and 14) respectively. It can be observed that, the development in roughness over the following years for both RAP and raw sections is unnoticeable such as sections 503 and 504 in Maryland, or increases at a slow rate such as sections 502 and 505 in Alabama. On the contrary, in dry climate that illustrated in Figures (15 and 16), the roughness develops faster yearly for both RAP and raw sections where the difference between them is larger than obtained in wet climate sections. This of course confirms the bad effect of dry climate on roughness progress in long term. The RAP performance is generally wobbly in both wet and dry climate where it can be observed that, mostly low pre-overlay curing provides a converging/better RAP performance against roughness in wet climate and a converging/worse RAP performance in dry climate. Thicker overlay thickness $(127 \mathrm{~mm})$ may contribute to more affinity between RAP and raw sections in both wet and dry climate. On the other hand, the preoverlay curing hasn't any obvious effect on roughness development in long run for both RAP and raw sections. From Table (6) that illustrates the statistical analysis for roughness development, it can be shown that, for wet climate, most RAP sections provides worse long term performance against roughness in Alabama except section 502, and provides better performance in Maryland except section 509. For dry climate, most RAP sections provide insignificant better or significant worse performance except section 508 .
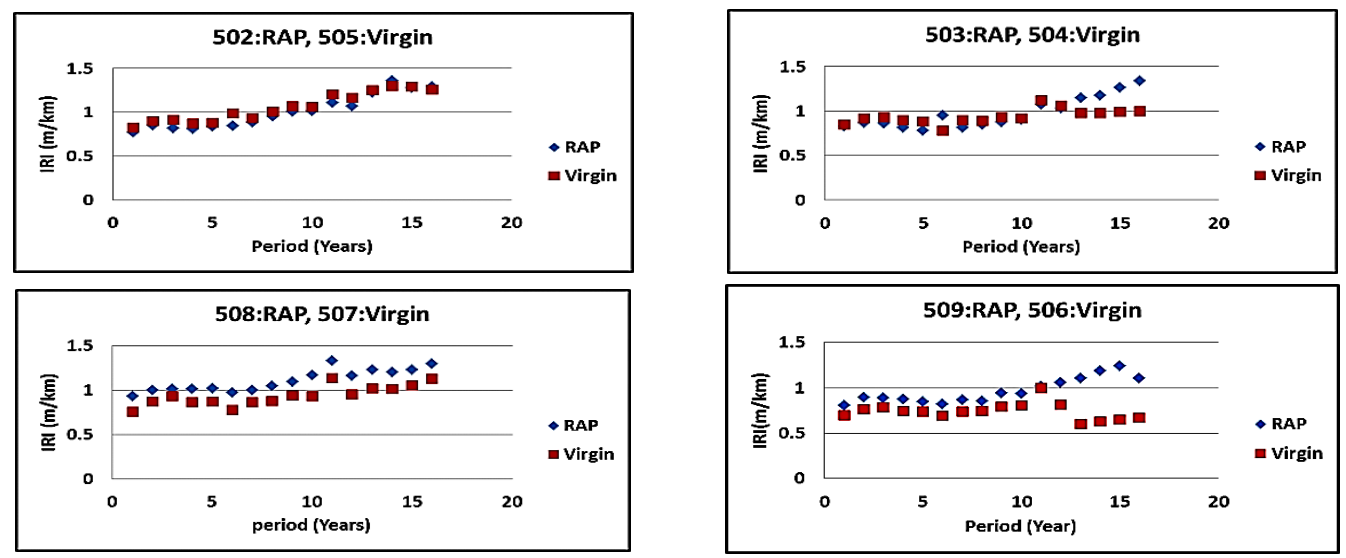

Figure 13- Roughness progress in Alabama (wet climate)
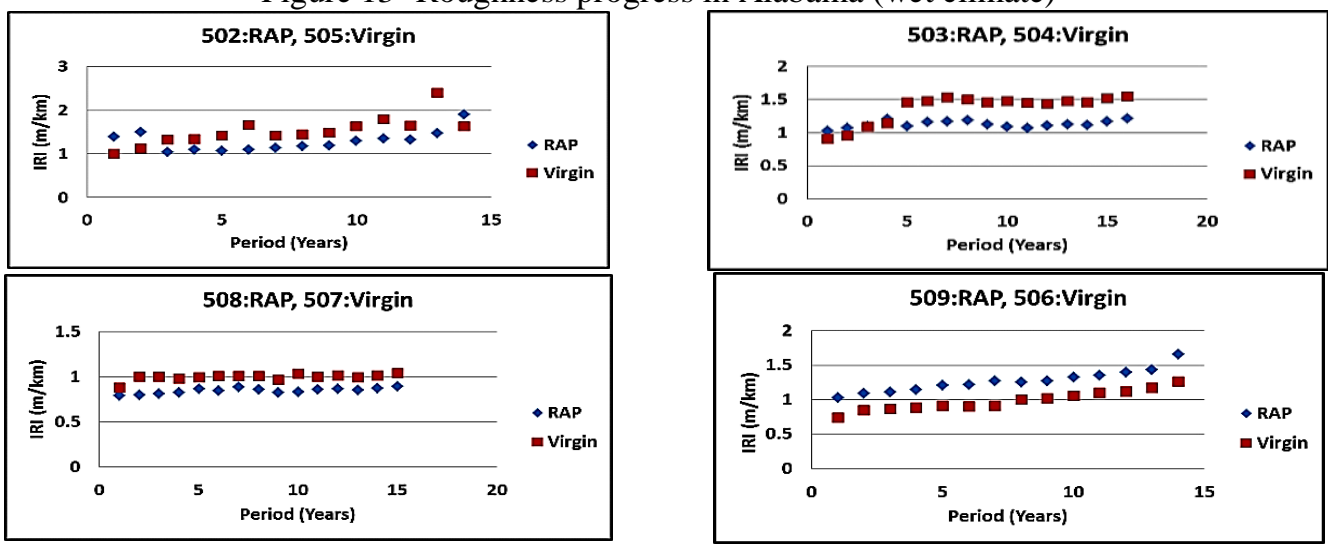

Figure 14- Roughness progress in Maryland (wet climate)
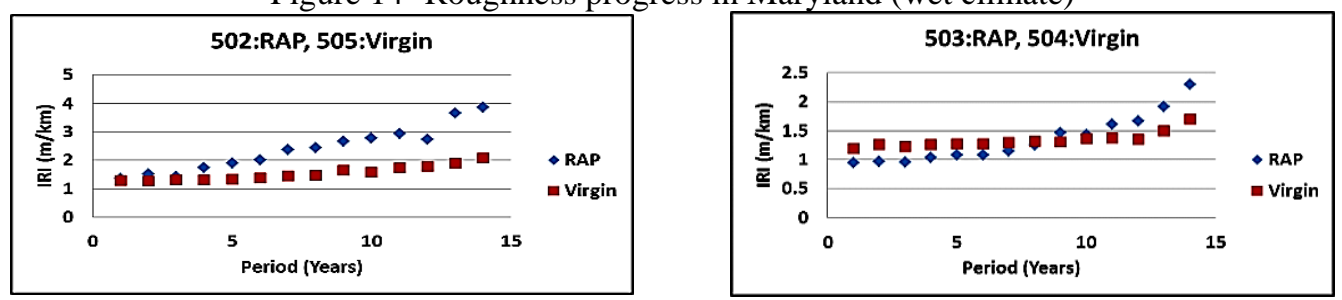

of asphalt overlays using reclaimed asphalt pavements $(R A P) "$
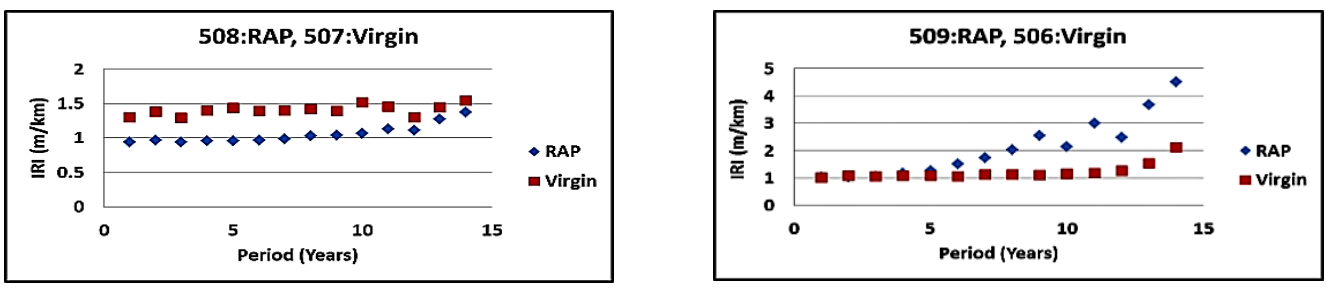

Figure 15- Roughness progress in Arizona (dry climate)
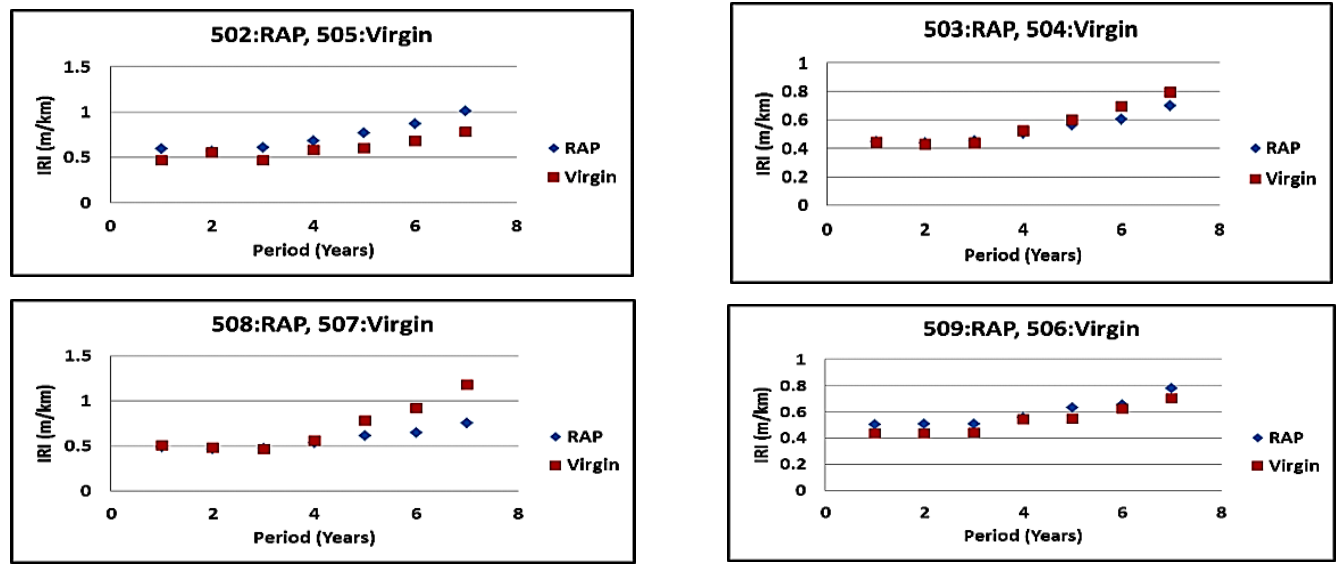

Figure 16- Roughness progress in New Mexico (dry climate)

Table 6- Paired $t$-Tests and $\mathrm{p}$-values for roughness development

\begin{tabular}{|c|c|c|c|c|c|c|c|c|c|c|}
\hline Climate & Site & Sections & $\begin{array}{l}\text { Mean } \\
\text { diff. } \\
\text { (m) }\end{array}$ & Sd & SE & $\begin{array}{c}\mathrm{t}- \\
\text { value }\end{array}$ & df & $\begin{array}{l}\text { p-value } \\
(\alpha=0.05)\end{array}$ & $\begin{array}{c}\text { Signifi- } \\
\text { cance }\end{array}$ & $\begin{array}{l}\text { Better } \\
\text { Perfor. }\end{array}$ \\
\hline \multirow{8}{*}{ 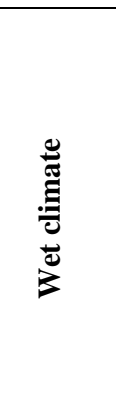 } & \multirow{4}{*}{ 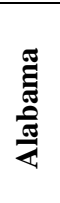 } & $502-505$ & -0.048 & 0.0494 & 0.0123 & -3.901 & 15 & 0.001 & Sign. & RAP \\
\hline & & $503-504$ & 0.0353 & 0.1419 & 0.0355 & 0.996 & 15 & 0.335 & Insign. & Raw \\
\hline & & $508-507$ & 0.1704 & 0.0386 & 0.0096 & 17.683 & 15 & 0.000 & Sign. & Raw \\
\hline & & $509-506$ & 0.2232 & 0.1860 & 0.0465 & 4.799 & 15 & 0.000 & Sign. & Raw \\
\hline & \multirow{4}{*}{ 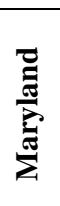 } & $502-505$ & -0.234 & 0.3603 & 0.0963 & -2.429 & 13 & 0.030 & Sign. & RAP \\
\hline & & 503-504 & -0.239 & 0.1918 & 0.0479 & -4.988 & 15 & 0.000 & Sign. & RAP \\
\hline & & 508-507 & -0.151 & 0.0301 & 0.0078 & $\begin{array}{l}-19.48 \\
\end{array}$ & 14 & 0.000 & Sign. & RAP \\
\hline & & $509-506$ & 0.285 & 0.0456 & 0.0122 & 23.40 & 13 & 0.000 & Sign. & Raw \\
\hline \multirow{8}{*}{ 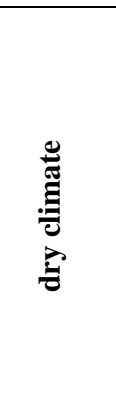 } & \multirow{4}{*}{ 䒿 } & $502-505$ & 0.8434 & 0.5394 & 0.1442 & 5.850 & 13 & 0.000 & Sign. & Raw \\
\hline & & $503-504$ & 0.0119 & 0.2903 & 0.0776 & 0.154 & 13 & 0.880 & Insign. & Raw \\
\hline & & $508-507$ & -0.351 & 0.1057 & 0.0283 & -12.43 & 13 & 0.000 & Sign. & RAP \\
\hline & & 509-506 & 0.8706 & 0.8296 & 0.2217 & 3.927 & 13 & 0.002 & Sign. & Raw \\
\hline & \multirow{4}{*}{ 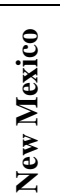 } & $502-505$ & 0.1387 & 0.0674 & 0.0255 & 5.443 & 6 & 0.002 & Sign. & Raw \\
\hline & & 503-504 & -0.029 & 0.0444 & 0.0168 & -1.738 & 6 & 0.133 & Insign. & RAP \\
\hline & & $508-507$ & -0.132 & 0.1643 & 0.0621 & -2.123 & 6 & 0.078 & Insign. & RAP \\
\hline & & $509-506$ & 0.0591 & 0.0268 & 0.0101 & 5.836 & 6 & 0.001 & Sign. & Raw \\
\hline
\end{tabular}




\section{Ahmed E. Abu El-Maaty, Alaa B. Fathy and Saad A. El-Hamrawy "Evaluating the long performance of asphalt overlays using reclaimed asphalt pavements $(R A P) "$}

\section{ANOVA Analysis}

ANOVA model is used in this study to measure the magnitude of the variation between sections using mixtures containing $30 \%$ RAP and sections using raw materials. Utilizing means of values in ANOVA provides more emphasis to the impact of each variable separately such as overlay thickness, preoverlay preparation and climate. By SPSS program, this test can be carried out to produce the means of each distress values as shown in Table (7). RAP mixtures provide worse performance for all indicators in varying proportions. The increase ratios in each distress due to using RAP as compared to raw materials shown in Figure (17) illustrate that the best RAP performance is achieved in roughness followed by rutting, longitudinal and fatigue cracking respectively.

Table 7- ANOVA results under all variables

\begin{tabular}{|l|c|c|}
\hline Distress mean & RAP & Raw \\
\hline Fatigue cracking $\left(\mathrm{m}^{2}\right)$ & 24.8 & 13.9 \\
\hline Longitudinal cracking $(\mathrm{m})$ & 100.8 & 67.2 \\
\hline Rutting $(\mathrm{mm})$ & 5.7 & 4.7 \\
\hline Roughness IRI (m/km) & 1.1 & 1.0 \\
\hline
\end{tabular}

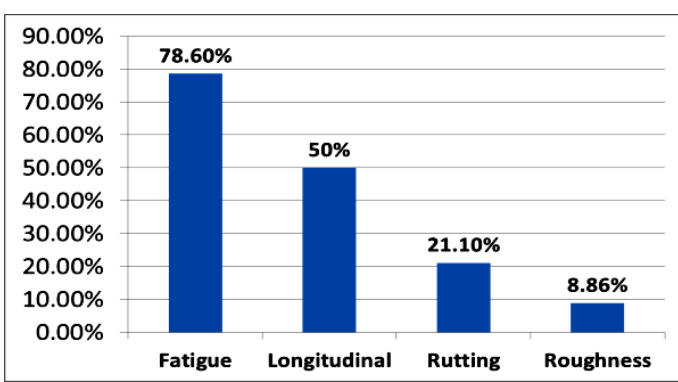

Figure 17- Overall increase ratios for RAP sections

The effect of climate on each mean distress increase ratios for RAP sections shown in Figure (18) illustrates that the RAP performance in wet and dry climates is approximately the same for both rutting and roughness. Adding RAP achieves significant better performance against fatigue cracking in dry climate and significant worse performance for longitudinal cracking. Figures (19 and 20) show the impact of overlay thickness and pre-overlay curing respectively. It can be concluded that the RAP sections provided better performance at thinner overlay thickness $(51 \mathrm{~mm})$ as well as at no/low preoverlay curing for all distresses. Worse RAP performance is achieved at thicker thickness $(127 \mathrm{~mm})$ and heavy pre-overlay curing at fatigue cracking only. According to the three studied variables, it is clear that the variation in pre-overlay curing (from low to heavy) followed by overlay thickness variation (from 51 to $127 \mathrm{~mm}$ ) have the highest statistical effect on fatigue cracking increasing. While the variation in climate from wet to dry has a significant statistical effect on reducing fatigue cracking and increasing longitudinal cracking. The Rutting and roughness progresses aren't clearly affected by variation in climate, thickness or curing.

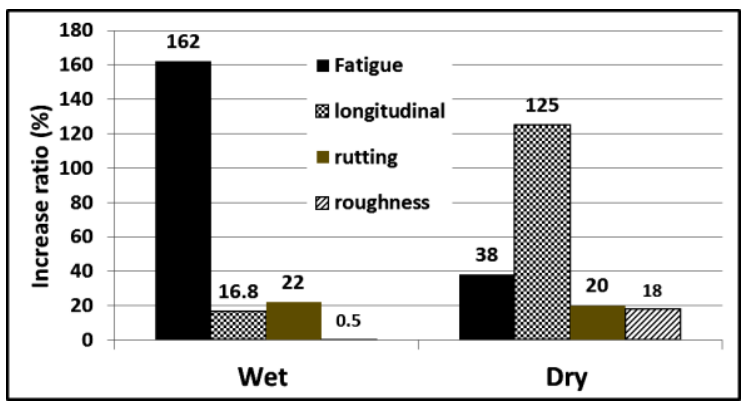

Figure 18- Climate effect on the increase ratios of RAP sections for each distress

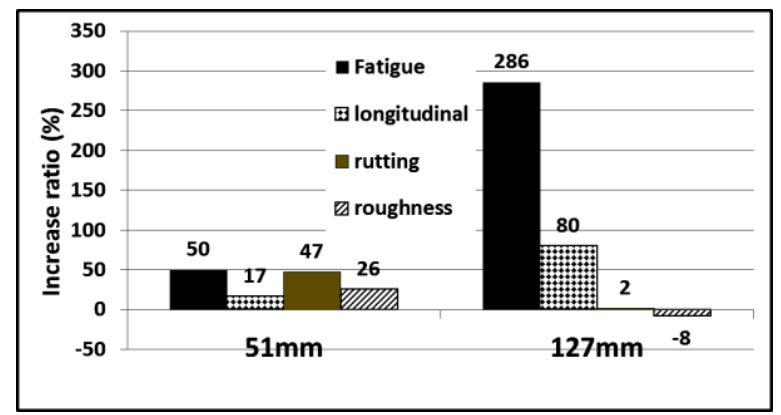

Figure 19- Overlay thickness effect on the increase ratios of RAP sections for each distress

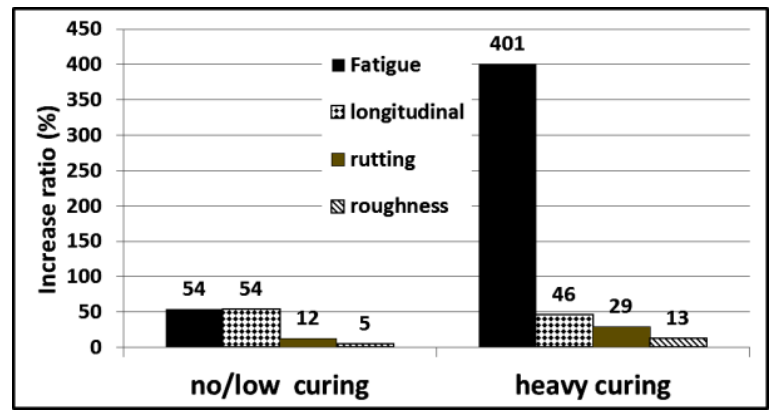

Figure 20- Pre-overlay curing effect on the increase ratios of RAP sections for each distress 


\section{Conclusions}

In this study, the performance of asphalt overlay including 30\% RAP was compared with overlay constructed using raw materials only in long run using LTPP database. Two overlay thicknesses (thin: $51 \mathrm{~mm}$ and thick: $127 \mathrm{~mm}$ ), two surface curing methods before rehabilitation (no/low and heavy grinding) and two climates (wet and dry/not freeze representing the Egyptian climate) were investigated. The statistical analysis using the paired t-tests, pvalues and ANOVA analysis were achieved to determine the priority in performance and the significance in variation. The main conclusions are shown as following:

1. Overlay material types had an obvious effect on the performance of flexible pavement. According to fatigue cracking progress, most RAP sections performed worse than or identical with raw sections in both wet and dry climates especially at terminal observed periods. For longitudinal cracking, most RAP sections improved the performance of asphalt overlay as compared with raw sections in wet climate, but performed worse than raw sections in dry climate. Considering rutting development, most RAP overlay sections constructed over a heavy grinded surface in wet climate provided higher rutting development in the long term while no/low pre-overlay curing achieved rutting values convergent with raw sections. For roughness development, most RAP and raw overlay sections in wet climate provided an unnoticeable or slightly increase development in long term, while in dry climate, the roughness developed faster for both RAP and raw sections where the difference between them was higher than shown in wet climate. This emphasizes the poor effect of dry climate on roughness progress in long run.

2. Thicker overlay $(127 \mathrm{~mm})$ for RAP sections provided lower fatigue cracking progress as compared with thinner thickness $(51 \mathrm{~mm})$. While thinner overlay $(51 \mathrm{~mm})$ for RAP sections obtained better long-term performance for longitudinal cracking development. According to rutting, the overlay thickness didn't have any obvious effect in both wet and dry climate. For roughness development, thicker overlay thickness might contribute to more affinity between RAP and raw sections.

3. The surface grinding before rehabilitation didn't appear any noticeable difference in fatigue, and longitudinal cracking development. According to rutting development in dry climate, the preoverlay curing had a wobbling impact where they provided slight worse performance in Arizona and convergent (slight better) performance in New Mexico. Considering roughness development, most RAP sections constructed after no/low surface curing achieved converging/better performance in wet climate and a converging/worse performance in dry climate.

4. The second analytical method used in this study was a statistic method using the paired-sample ttest. Generally, RAP sections achieved better insignificant performance against fatigue cracking in dry climate while obtained worse significant performance in wet climate. For longitudinal cracking, it performed significantly worse than raw sections for both wet and dry climates. For rutting progress, the pre-overlay curing provided significant worse performance for most RAP sections in wet climate, while in dry climate, most RAP sections performed significantly worse than or convergent with raw sections. According to roughness development, most RAP sections provided insignificant better or significant worse performance in dry climate.

5. The third analytical method used in this study was ANOVA analysis. According to ANOVA results, RAP mixtures performed worse than raw mixtures especially for fatigue and longitudinal cracking respectively. The variation in preoverlay curing (from low to heavy) had the highest statistical effect on fatigue cracking increasing, while rutting and roughness progresses weren't clearly affected by variation in climate, thickness or surface curing before rehabilitation. The variation in climate from wet to dry had a significant statistical effect on reducing fatigue cracking and increasing longitudinal cracking.

\section{References}

[1] Kang-Won Wayne Lee, Kathleen Wilson and Syed Amir Hassan, Prediction of performance and evaluation of flexible pavement rehabilitation strategies, Journal of Traffic and Transportation Engineering (English Edition), Volume 4, Issue 2, Pages 178-184, 2017.

[2] Jan Mikolaj, Lubos Remek, and Marian Macula, Asphalt Concrete Overlay Optimization Based on Pavement Performance Models, Advances in Materials Science and Engineering, Article ID 6063508, 2017. 

of asphalt overlays using reclaimed asphalt pavements $(R A P) "$

[3] Yuhong Wang, The effects of using reclaimed asphalt pavements (RAP) on the long-term performance of asphalt concrete overlays, Construction and Building Materials, 120 (2016) 335-348, 2016.

[4] James Bryce, Gonzalo Rada and Gary Hicks, Effect of preservation treatments on pavement performance, pavement and asset management, Taylor and Francis group, 2019.

[5] FHWA report. Applied research associates, statistical analysis of performance of recycled hot mix asphalt overlays in flexible pavement rehabilitation. FHWA Product Distribution Center, FHWA-HRT-11-051, 2011.

[6] Regis L. Carvalho, Hamid Shirazi, Manuel Ayres, and Olga Selezneva, Performance of Recycled Hot-Mix Asphalt Overlays in Rehabilitation of Flexible Pavements, journal of the Transportation Research Board, Volume: 2155 issue: 1, 55-62, 2010.

[7] Jerome F. Daleiden, Amy Simpson, and. Brent Rauhut, Rehabilitation performance trends: early observation from long-term pavement performance (LTPP) specific pavement studied (SPS), Technical Report Documentation, FHWA-RD-97-099, 1998.

[8] Umme Amina Mannan ; and Rafiqul A. Tarefder, Evaluation of Long-Term Pavement Performance Based on New Mexico LTPP SPS5 Data, Second Transportation \& Development Congress, 2014.

[9] 9. Randy West, Jenna Michael, Rod Turochy, and Saeed Maghsoodloo. Use of data from specific pavement studies experiment 5 in the long-term pavement performance program to compare virgin and recycled asphalt pavements. Journal of the Transportation Research Board, pp. 82-89, 2011.

[10] Kathleen T. Hall, Carlos E. Correa, Amy L. Simpson, Performance of Flexible Pavement Rehabilitation Treatments in the Long-Term Pavement Performance SPS-5 Experiment, Journal of the Transportation Research Board, Volume: 1823 issue: 1, 93-101, 2003.

[11] Harold L. Von Quintus, Amy L. Simpson, Ahmed A. Eltahan, Rehabilitation of Asphalt Concrete Pavements: Initial Evaluation of the SPS-5 Experiment-Final Report, Federal Highway Administration, FHWA-RD-01-168, 2006.

[12] Fouad Bayomy, Hassan Salem and Lacy Vosti , Analysis of the Long-Term Pavement Performance Data for the Idaho GPS and SPS Sections, Idaho Transportation Department, 2007.
[13] Hongren Gong, Qiao Dong, Baoshan Huang and Xiaoyang Jia, Effectiveness Analyses of Flexible Pavement Preventive Maintenance Treatments with LTPP SPS-3 Experiment Data, Journal of Transportation Engineering 142(2), 2016.

[14] Kottek, M., J. Grieser, C. Beck, B. Rudolf, and F. Rubel. World map of the Köppen-Geiger climate classification updated. Meteorologische Zeitschrift, Vol. 15, 259-263, 2006.

[15] Rosie Shier, Statistics: 1.1 paired t-tests, Mathematics learning support center, 2004

[16] Eva Ostertagová and Oskar Ostertag. Methodology and Application of One-way ANOVA. American Journal of Mechanical Engineering, Vol. 1, No. 7, 256-261, 2013.

[17] Mohamed R. Elbheiry, Khaled A. Kandil, Akram S. Kotb. Investigation of factors affecting pavement roughness. Engineering Research Journal, 132, 2011.

[18] Christopher M. Raymond, Susan L. Tighe, Ralph Haas and Leo Rothenburg, Analysis of Influences on As-built Pavement Roughness in Asphalt Overlays, International Journal of Pavement Engineering, Volume 4, 2003 - Issue 4, 181-192, 2007. 